\title{
Profil Klinis Anak dengan Demam Tifoid di Rumah Sakit Umum Pusat Dr Sardjito Yogyakarta
}

Rianti Puji Lestari, Eggi Arguni

Bagian Ilmu Kesehatan Anak Fakultas Kedokteran Universitas Gadjah Mada/RSUP Dr. Sardjito, Yogyakarta

Latar belakang. Demam tifoid masih merupakan masalah kesehatan masyarakat yang penting di Indonesia. Gambaran klinis tifoid sangat bervariasi, seperti gejala klinis ringan hingga berat yang disertai komplikasi.

Tujuan. Untuk mengetahui gambaran manifestasi klinis, laboratorium, dan tata laksana DT anak yang dirawat di RSUP Dr. Sardjito. Metode. Penelitian retrospektif ini dilakukan menggunakan data rekam medis pasien DT anak yang menjalani rawat inap sejak Januari 2011 hingga Mei 2016.

Hasil. Ditemukan 158 kasus DT yang terbukti secara serologis (96,8\%), kultur darah (1,3\%), maupun keduanya (1,9\%). Demam merupakan gejala utama pada seluruh pasien. Gejala penyerta lain adalah anoreksia $(54,4 \%)$, mual $(49,4 \%)$, muntah (41,8\%), nyeri kepala $(37,3 \%)$, batuk $(37,3 \%)$, nyeri perut $(34,2 \%)$, konstipasi $(30,4 \%)$, dan diare $(29,7 \%)$. Tanda yang paling sering didapatkan adalah pembesaran hati (29,7\%), nyeri tekan abdomen (20,3\%), limfadenopati (13,3\%), letargi (13,3\%), lidah kotor (12,0\%), pembesaran limpa $(6,3 \%)$ dan penurunan kesadaran (4,4\%). Rerata lama rawat inap adalah 8,4 $\pm 6,2$ hari, mortalitas $2,5 \%$ diakibatkan oleh sepsis berat. Respon pasien $81,0 \%$ terhadap pemberian antibiotik, terbanyak diresepkan adalah ceftriaxone (45,6\%). Komplikasi berupa sepsis $(10,1 \%)$, hepatitis $(8,9 \%)$, perdarahan saluran cerna $(5,7 \%)$, ensefalopati $(4,4 \%)$, dan perforasi usus $(0,6 \%)$.

Kesimpulan. Profil klinis anak dengan DT serupa dengan gambaran umum pasien di daerah endemis. Penegakan diagnosis pasti dengan menggunakan kultur darah masih belum banyak membantu di rumah sakit kami. Mortalitas yang masih cukup tinggi perlu diteliti lebih lanjut untuk perbaikan prognosis pasien. Sari Pediatri 2017;19(3):139-44

Kata kunci: profil klinis, demam tifoid, anak

\section{Clinical Profile of Typhoid Fever in Children at Dr Sardjito General Hospital Yogyakarta}

Rianti Puji Lestari, Eggi Arguni

Background. Typhoid fever is a major health problem in Indonesia. The clinical feature varies greatly, from mild to severe symptoms with some complications.

Objective. To assess the clinical presentations, laboratory results, and treatment of typhoid fever in children at Dr Sardjito General Hospital.

Methods. A retrospective observational study was conducted at Dr Sardjito General Hospital by reviewing medical records of all in-patients children who were diagnosed with typhoid fever from January 2011 to May 2016.

Results. There were 158 cases of typhoid fever that were confirmed by serological test $(96,8 \%)$, blood culture $(1,3 \%)$, or both (1,9\%). Fever was the main symptom in all patients. The other symptoms were anorexia $(54,4 \%)$, nausea $(49,4 \%)$, vomiting $(41,8 \%)$, headache $(37,3 \%)$, cough $(37,3 \%)$, abdominal pain $(34,2 \%)$, constipation $(30,4 \%)$ and diarrhea $(29,7 \%)$. The signs observed in patients were liver enlargement $(29,7 \%)$, abdominal tenderness (20,3\%), lymphadenopathy (13,3\%), lethargy (13,3\%), typhoid tongue (12,0\%), spleen enlargement $(6,3 \%)$, and decrease level of consciousness $(4,4 \%)$. The mean length of stay in hospital was $8,4 \pm 6,2$ days. The mortality was 2,5\% which was caused by severe sepsis. Eighty one percent patients responded to single antibiotic, and the most common antibiotic prescribed was ceftriaxone (44.5\%). The complications found were sepsis (10,1\%), hepatitis $(8,9 \%)$, gastrointestinal bleeding $(5,7 \%)$, encephalopathy $(4,4 \%)$, and intestinal perforation $(0,6 \%)$.

Conclusion. Clinical profile of typhoid fever in children is similar with common pattern in other endemic areas. Blood culture is technically demanding and not much helpful to confirm diagnosis in our setting. The high mortality needs further investigation to improve patient prognosis. Sari Pediatri 2017;19(3):139-44

Keywords : clinical profile, typhoid fever, children

Alamat korespondensi: dr. Rianti Puji Lestari. Bagian Ilmu Kesehatan Anak, Fakultas Kedokteran Universitas Gadjah Mada / RSUP Dr. Sardjito, Jl. Kesehatan No.1 Sekip Yogyakarta 55284, Indonesia. Email: riantipujilestari@yahoo.co.id 
$\mathrm{D}$ emam tifoid (DT) merupakan masalah kesehatan masyarakat yang penting di sebagian besar negara berkembang di dunia, termasuk Indonesia. Angka kejadian cukup tinggi dan tidak sedikit anak yang memerlukan perawatan di rumah sakit. Besaran angka pasti kasus DT di dunia sangat sulit ditentukan karena penyakit ini dikenal mempunyai gejala dengan spektrum klinis yang sangat luas. Laporan badan kesehatan dunia $\mathrm{WHO}^{1}$ (2003), terdapat 17 juta kasus DT per tahun di dunia, jumlah kematian mencapai 600.000 (case fatality rate, $\mathrm{CFR}=3,5 \%$ ). Crump $\mathrm{dkk}^{2}$ melaporkan 21,7 juta kasus angka kejadian DT secara global dan menyebabkan 217.000 kematian per tahun. Pada tahun 2008, angka kesakitan DT di Indonesia dilaporkan 81,7 kasus per 100.000 penduduk dengan penderita terbanyak adalah kelompok usia 2-15 tahun. ${ }^{3}$

Penelitian sebelumnya menyebutkan bahwa 73,6\% kasus DT disebabkan Salmonella Typhi, sisanya disebabkan S. Paratyphi A $(15,1 \%), S$. Typhimurium (9,4\%), dan S. Enteritidis (1,9\%). ${ }^{4}$ Gambaran klinis tifoid sangat bervariasi, dari gejala ringan hingga berat yang disertai komplikasi. Gambaran klinis juga bervariasi berdasarkan daerah atau negara, serta menurut waktu. Manifestasi DT pada anak tidak seberat dewasa, tetapi DT yang mengalami komplikasi mortalitas meningkat sekitar $1 \%-5 \% .{ }^{5}$ Resistensi tubuh anak yang rendah dan faktor bakteri, khususnya jumlah bakteri yang masuk, virulensi, maupun resistensi bakteri terhadap antibiotik, dapat menyebabkan DT kadangkala menjadi berat. ${ }^{6}$

Diagnosis yang akurat untuk DT sangat diperlukan untuk manajemen pasien. Keterlambatan diagnosis dapat memperburuk keadaan pasien, bahkan jika tidak ditangani segera dapat menyebabkan kematian. Keterlambatan diagnosis dapat disebabkan oleh analisis gejala penyakit DT yang cukup sulit karena ada kemiripan gejala dengan penyakit lain. ${ }^{7}$ Pada keadaan tertentu dibutuhkan pemeriksaan tambahan untuk membantu penegakan diagnosis. Penegakan diagnosis sedini mungkin sangat bermanfaat agar bisa diberikan terapi yang tepat dan meminimalkan komplikasi.

Dari latar belakang di atas, peneliti tertarik untuk melakukan penelitian tentang profil klinis, laboratorium, dan luaran terapi pada anak dengan demam tifoid di RSUP dr Sardjito, Yogyakarta.

\section{Metode}

Penelitian deskriptif mengenai gambaran klinis, laboratorium, dan luaran terapi pada pasien DT anak yang dirawat di RSUP dr Sardjito. Pengambilan data rekam medis dilakukan secara retrospektif selama bulan Januari 2011 hingga Mei 2016. Subyek penelitian adalah pasien bayi/anak usia 0 hari sampai dengan 18 tahun. Diagnosis klinis dilakukan oleh dokter spesialis anak. Riwayat penyakit, profil klinis, terapi yang diberikan, serta komplikasi selama perawatan yang tercatat dalam rekam medis didokumentasikan. Kriteria inklusi untuk kelompok kasus adalah pasien penyakit DT yang telah tegak diagnosisnya berdasarkan hasil kultur darah maupun pemeriksaan Tubex ${ }^{\oplus}$ dan menjalani rawat inap di RSUP dr Sardjito dengan usia 0 hari sampai dengan 18 tahun. Pasien yang keluar dari rumah sakit secara paksa atas permintaan sendiri tidak diikutsertakan dalam penelitian. Data dimasukkan dan diolah menggunakan IBM SPSS Statistik 20.0. Variabel kontinu ditampilkan menggunakan rata-rata dan simpang deviasi. Variabel kategorikal ditampilkan sebagai persentase.

\section{Hasil}

Selama periode penelitian, terdapat 173 anak yang dirawat inap dengan diagnosis DT. Pada pemeriksaan laboratorium, 158 anak didapatkan hasil tes serologis positif, hasil kultur darah positif, maupun keduanya. Usia pasien saat terdiagnosis berkisar antara 5 bulan

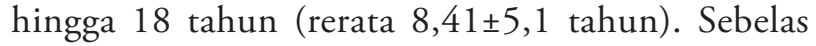
$(7 \%)$ pasien berusia kurang dari 2 tahun. Di antara 158 anak, 77 (48,7\%) anak laki-laki, dengan rasio laki-laki : perempuan adalah 0,95:1. Seluruh subjek penelitian belum pernah mendapat vaksinasi tifoid dan hanya 11 (7\%) subjek yang pernah terdiagnosis DT sebelumnya (Tabel 1).

Leukopenia dan leukositosis didapatkan masingmasing $15,8 \%$ dan 19,6\% subyek penelitian, dengan rerata leukosit $7955,3 \pm 4926,2 \mathrm{sel} / \mathrm{mm}^{3}$. Tigapuluh tiga $(20,9 \%)$ pasien mengalami anemia ringan, 8 $(5,1 \%)$ anemia sedang, dan $1(0,6 \%)$ pasien anemia berat. Rerata kadar $\mathrm{Hb}$ dan trombosit pasien adalah $11,9 \pm 2,1 \mathrm{~g} / \mathrm{dL}$ dan $211500,0 \pm 127991,0$ $\mathrm{sel} / \mathrm{mm}^{3}$. Tabel 2 menunjukkan hasil pemeriksaan laboratorium. 
Tabel 1. Karakteristik dasar subyek penelitian

\begin{tabular}{lcc}
\hline Karakteristik & Jumlah & Persentase (\%) \\
\hline Usia (tahun) & & \\
$\quad<5$ & 45 & 28,5 \\
$\quad>5$ & 113 & 71.5 \\
Jenis kelamin & 77 & 48,7 \\
Laki-laki & 81 & 51,3 \\
Perempuan & & \\
Status gizi & 112 & 70,9 \\
$\quad$ Normal & 28 & 17,7 \\
Kurang & 18 & 7,6 \\
$\quad$ Buruk & 4 & 2,5 \\
$\quad$ Lebih & 2 & 1,3 \\
$\quad$ Obese & & \\
Riwayat DT sebelumnya & 147 & 93,0 \\
Tidak pernah terdiagnosis demam tifoid & 11 & 7,0 \\
Pernah terdiagnosis demam tifoid & & \\
Vaksinasi tifoid & 0 & 0 \\
Pernah mendapat vaksinasi & 158 & 100 \\
Tidak pernah mendapat vaksinasi & & \\
Sumber air minum & 18 & 11,4 \\
$\quad$ PDAM & 55 & 34,8 \\
$\quad$ Air sumur & 85 & 53,8 \\
$\quad$ Lain-lain & & \\
\hline
\end{tabular}

Tabel 2. Hasil pemeriksaan laboratorium

\begin{tabular}{|c|c|c|}
\hline Hasil laboratorium & Jumlah & Persentase (\%) \\
\hline \multicolumn{3}{|l|}{ Leukosit (sel/mm³) } \\
\hline$<4000$ & 25 & 15,8 \\
\hline $4000-11000$ & 102 & 64,6 \\
\hline$>11000$ & 31 & 19,6 \\
\hline \multicolumn{3}{|l|}{ Kadar $\mathrm{Hb}(\mathrm{g} / \mathrm{dL})$} \\
\hline$<7$ & 1 & 0,6 \\
\hline 7-8.9 & 8 & 5,1 \\
\hline $9-11$ & 33 & 20,9 \\
\hline$>11$ & 116 & 73,4 \\
\hline \multicolumn{3}{|l|}{ Kadar trombosit $\left(\mathrm{sel} / \mathrm{mm}^{3}\right)$} \\
\hline$<150000$ & 55 & 34,8 \\
\hline$>150000$ & 103 & 65,2 \\
\hline \multicolumn{3}{|l|}{ Konfirmasi diagnosis } \\
\hline Kultur Salmonella typhi positif & 2 & 1,3 \\
\hline Tubex $^{\oplus}$ positif & 153 & 96,8 \\
\hline Keduanya positif & 3 & 1,9 \\
\hline
\end{tabular}

Demam merupakan keluhan utama pada seluruh pasien (100\%), keluhan lain yang sering didapatkan berupa anoreksia $(54,4 \%)$, mual $(49,4 \%)$, muntah $(41,8 \%)$, nyeri kepala $(37,3 \%)$, batuk $(37,3 \%)$, nyeri perut $(34,2 \%)$, konstipasi $(30,4 \%)$ dan diare $(29,7 \%)$. Tanda yang paling sering didapatkan pada pasien adalah pembesaran hati $(29,7 \%)$, nyeri tekan abdomen (20,3\%), limfadenopati (13,3\%), letargi $(13,3 \%)$, lidah kotor $(12,0 \%)$, pembesaran limpa $(6,3 \%)$ dan penurunan kesadaran $(4,4 \%)$. Rose spot tidak ditemukan pada seluruh subjek (Tabel 3 dan Tabel 4). 
Rianti Puji Lestari dkk: Profil klinis anak dengan demam tifoid

Tabel 3. Gejala yang muncul pada subjek

\begin{tabular}{lccc}
\hline Gejala & $\begin{array}{c}\text { Semua subjek } \mathrm{n}=158, \\
(\%)\end{array}$ & $\begin{array}{c}\text { Usia }<5 \text { tahun } \mathrm{n}=45, \\
(\%)\end{array}$ & $\begin{array}{c}\text { Usia }>5 \text { tahun } \mathrm{n}=113, \\
(\%)\end{array}$ \\
\hline Demam & $158(100)$ & $45(100)$ & $113(100)$ \\
Batuk & $59(37,3)$ & $20(44,4)$ & $39(34,5)$ \\
Diare & $47(29,7)$ & $15(33,3)$ & $32(28,3)$ \\
Konstipasi & $48(30,4)$ & $12(26,7)$ & $36(31,9)$ \\
Nyeri kepala & $59(57,3)$ & $4(8,9)$ & $55(48,7)$ \\
Nyeri perut & $54(34,2)$ & $9(20,0)$ & $45(39,8)$ \\
Mual & $78(49,4)$ & $14(31,1)$ & $64(56,6)$ \\
Muntah & $66(41,8)$ & $19(42,2)$ & $47(41,6)$ \\
Anoreksia & $86(54,4)$ & $25(55,6)$ & $61(54,0)$ \\
\hline
\end{tabular}

Tabel 4. Tanda yang muncul pada subjek

\begin{tabular}{lccc}
\hline Gejala & $\begin{array}{c}\text { Semua pasien } \\
(\mathrm{n}=158), \mathrm{n}(\%)\end{array}$ & $\begin{array}{c}\text { Pasien }<5 \text { tahun } \\
(\mathrm{n}=45), \mathrm{n}(\%)\end{array}$ & $\begin{array}{c}\text { Pasien }>5 \text { tahun } \\
(\mathrm{n}=113), \mathrm{n}(\%)\end{array}$ \\
\hline Penurunan kesadaran & $7(4,4)$ & $1(2,2)$ & $6(5,3)$ \\
Letargi & $21(13,3)$ & $2(4,4)$ & $19(16,8)$ \\
Limfadenopati & $21(13,3)$ & $5(11,1)$ & $16(14,2)$ \\
Lidah kotor & $19(12,0)$ & $5(11,1)$ & $14(12,4)$ \\
Hepatomegali & $47(29,7)$ & $10(22,2)$ & $37(32,7)$ \\
Splenomegali & $10(6,3)$ & $4(8,9)$ & $6(5,3)$ \\
Nyeri tekan abdomen & $32(20,3)$ & $2(4,4)$ & $30(26,5)$ \\
Rose spot & $0(0,0)$ & $0(0,0)$ & $0(0,0)$ \\
\hline
\end{tabular}

Di antara total 158 pasien yang dilakukan kultur darah, $45(28,5 \%)$ kultur urin, $14(8,9 \%)$ kultur feses, $10(6,3 \%)$ kultur liquor cerebrospinalis, 2 (1,3\%), dan kultur discharge stoma $1(0,6 \%)$ pasien. Lima pasien mempunyai hasil kultur darah yang positif untuk Salmonella Typhi, sementara hasil kultur selain darah negatif untuk kuman tersebut. Dari kelima hasil kultur darah yang positif untuk Salmonella Typhi, seluruhnya sensitif terhadap ampisilin, ampisilin-sulbaktam, cefepime, ceftazidime, ceftriaxone, dan ciprofloxacin. Dua $(40 \%)$ pasien sensitif terhadap amoksisilin maupun kloramfenikol, sementara $3(60 \%)$ pasien menunjukkan resistensi terhadap amikasin, cefazolin, dan gentamicin.

Respon terhadap pemberian antibiotik tunggal $81,0 \%$ pasien, terbanyak diresepkan adalah ceftriaxone $(45,6 \%)$. Delapan puluh tiga pasien $(52,5 \%)$ mengalami bebas demam setelah pemberian antibiotik pertama dalam 3 hari atau kurang, dan 50 (31,6\%) mengalami bebas demam setelah 4-6 hari. Hanya 25 $(15,8 \%)$ pasien yang mengalami periode demam $\geq 7$ hari setelah pemberian antibiotik. Komplikasi yang ditemukan berupa sepsis $(10,1 \%)$, hepatitis $(8,9 \%)$,
Tabel 5. Frekuensi komplikasi yang ditemukan pada subjek

\begin{tabular}{lc}
\hline Komplikasi & Jumlah subjek (\%) \\
\hline Hepatitis & $14(8,9)$ \\
Ensefalopati & $7(4,4)$ \\
Appendicitis & $0(0,0)$ \\
Perdarahan saluran cerna & $9(5,7)$ \\
Sepsis/syok septik & $16(10,1)$ \\
Perforasi & $1(0,6)$ \\
\hline
\end{tabular}

perdarahan saluran cerna $(5,7 \%)$, ensefalopati $(4,4 \%)$, dan perforasi usus $(0,6 \%)$. Rerata lama rawat inap di rumah sakit adalah $8,4 \pm 6,2$ hari, dengan mortalitas $2,5 \%$ yang diakibatkan oleh sepsis berat.

\section{Pembahasan}

Sebagian besar pasien yang terdiagnosis DT berada dalam kelompok umur $>5$ tahun, rerata usia saat presentasi adalah $8,4 \pm 5,1$ tahun. Hal tersebut mirip dengan studi sebelumnya yang melaporkan bahwa sebagian besar pasien terdiagnosis saat usia 6-10 tahun. ${ }^{8}$ 
Diduga karena usia tersebut rentan terpapar makanan atau minuman yang tercemar oleh kuman Salmonella Typhi. Rasio laki-laki:perempuan adalah 0,95:1, mirip dengan hasil penelitian Modi, ${ }^{8}$ sementara beberapa penelitian lain seperti Comeau $\mathrm{dkk}^{9}$ dan Koul dkk ${ }^{10}$ didominasi laki-laki.

Hasil kultur darah positif untuk Salmonella Typhi ditemukan hanya 5 pasien. Namun, kultur darah tidak dilakukan pada seluruh pasien sehingga karena data yang ada tidak lengkap. Selain itu, penggunaan antibiotik, waktu dan teknik pengambilan sampel dapat memengaruhi hasil kultur, di samping memakan waktu, biaya, dan keterbatasan alat. Oleh karena itu, pemeriksaan klinis dan serologis seperti Tubex masih sangat membantu untuk menegakkan diagnosis. Hasil tersebut serupa dengan hasil studi Modi ${ }^{8}$ yang melaporkan kultur darah positif pada $4,1 \%$ subjek penelitian.

Demam merupakan keluhan yang didapatkan seluruh pasien. Hal tersebut serupa dengan beberapa penelitian sebelumnya, seperti Modi, ${ }^{8}$ Comeau dkk, ${ }^{9}$ Malik dan Malik, ${ }^{11}$ dan Patankar dan Shah. ${ }^{12}$ Keluhan gastrointestinal merupakan keluhan terbanyak kedua yang didapatkan pada pasien, meliputi anoreksia (54,4\%), mual (49,4\%), dan muntah (41,8\%). Modi ${ }^{8}$ melaporkan bahwa keluhan gastrointestinal tersering ditemukan adalah nyeri perut $(57,1 \%)$ dan muntah (50\%), begitu pula dengan penelitian Comeau $\mathrm{dkk}^{9}$ Pada penelitian kami, nyeri perut ditemukan pada $34,2 \%$ pasien dan konstipasi pada 30,4\% pasien. Konstipasi tidak ditemukan pada penelitian Patankar dan Shah, ${ }^{12}$ ditemukan $2 \%$ pada penelitian Modi, ${ }^{8}$ $11,2 \%$ pada penelitian Taneja dkk, ${ }^{13}$ dan $12,8 \%$ pada penelitian Comeau dkk. ${ }^{9}$

Tanda yang paling sering didapatkan pada pasien adalah pembesaran hati $(29,7 \%)$, nyeri tekan abdomen (20,3\%), limfadenopati $(13,3 \%)$, letargi $(13,3 \%)$, lidah kotor $(12,0 \%)$, pembesaran limpa $(6,3 \%)$ dan penurunan kesadaran $(4,4 \%)$. Menurut penelitian Modi, tanda yang paling banyak didapatkan adalah wajah toksik (92\%) dan lidah kotor $(66,3 \%)$, pembesaran hati didapatkan sebanyak $36,7 \%{ }^{8}$ Sementara itu, Taneja $\mathrm{dkk}^{13}$ melaporkan bahwa lidah kotor didapatkan pada $81,2 \%$ pasien. Serupa dengan hasil penelitian sebelumnya, penelitian kami tidak mendapatkan rose spot pada seluruh subjek. ${ }^{8} \mathrm{Hal}$ tersebut mungkin karena warna kulit kecoklatan pada sebagian besar orang Indonesia.
Komplikasi kami temukan pada 29,7\% subjek, lebih banyak bila dibandingkan penelitian Modi $(8,1 \%)^{8}$ dan Patankar dan Shah $(18,8 \%) .{ }^{12}$ Namun, Comeau $\mathrm{dkk}^{9}$ melaporkan komplikasi lebih banyak $(38,5 \%)$. Komplikasi yang ditemukan pada penelitian ini berupa sepsis $(10,1 \%)$, hepatitis $(8,9 \%)$, perdarahan saluran cerna $(5,7 \%)$, ensefalopati $(4,4 \%)$, dan perforasi usus $(0,6 \%)$. Demam tifoid dapat menyebabkan komplikasi yang lebih berat, seperti syok septik dan acute respiratory distress syndrome (ARDS). Bila tidak diterapi, mortalitas dapat mencapai 12\%-30\%. ${ }^{14}$ Mortalitas kami temukan pada 2,5\% kasus yang diakibatkan oleh sepsis berat.

Pemberian antibiotik empiris yang tepat pada pasien DT sangat penting karena dapat mencegah komplikasi dan mengurangi angka kematian. ${ }^{15}$ Banyak faktor yang dipertimbangkan dalam pemilihan terapi, antara lain, faktor biaya, ketersediaan obat, efikasi, kekambuhan, dan kemungkinan adanya multidrug resistant Salmonella Typhi (MDRST). Beberapa antibiotik lini pertama yang banyak digunakan, antara lain, kloramfenikol, ampisilin, dan kotrimoksazol. Namun, saat ini banyak dilaporkan adanya MDRST, seperti di Pakistan, Mesir, dan Thailand. Beberapa penelitian di Indonesia menunjukkan bahwa kloramfenikol masih merupakan terapi lini pertama untuk DT. ${ }^{16,17}$ Namun, resistensi terhadap kloramfenikol juga dilaporkan di beberapa tempat. ${ }^{18,19}$ Meskipun belum ada data mengenai kasus MDRST di Indonesia, Erviani ${ }^{20}$ melaporkan bahwa di antara 30 pasien dengan infeksi Salmonella Typhi di tiga rumah sakit dan puskesmas di Makassar, ditemukan multidrug resistensi terhadap kloramfenikol dan ampisilin pada 33,3\% kasus dengan metode disc diffusion dan multiplex PCR. Pada kasus MDRST, pilihan terapi lini kedua adalah ceftriaxone atau quinolon. Namun, penggunaan quinolon masih kontroversi untuk anak mengingat salah satu efek sampingnya adalah artropati. Oleh sebeb itu, ceftriaxone menjadi pilihan pertama untuk DT anak. Beberapa penelitian menunjukkan pemberian ceftriaxone sebagai terapi empiris pada pasien anak yang dirawat di rumah sakit secara bermakna dapat mengurangi lama pengobatan dibandingkan dengan pemberian kloramfenikol jangka panjang, dengan efek samping dan angka kekambuhan yang lebih rendah, serta lama demam turun yang lebih cepat. ${ }^{15,21-26}$ Pengetahuan dan penilaian klinis yang baik diperlukan dalam pemilihan terapi empiris yang tepat terutama bila uji resistensi tidak memadai. 
Rianti Puji Lestari dkk: Profil klinis anak dengan demam tifoid

\section{Kesimpulan}

Profil klinis anak dengan demam tifoid di RSUP Dr. Sardjito Yogyakarta serupa dengan gambaran umum pasien di daerah endemis. Penegakan diagnosis pasti dengan menggunakan kultur darah masih belum banyak membantu. Mortalitas yang masih cukup tinggi perlu diteliti lebih lanjut untuk perbaikan prognosis pasien.

\section{Daftar pustaka}

1. World Health Organization. Background document: The diagnosis, treatment and prevention of typhoid fever. Didapat dari: www.who.int/rpc/TFGuideWHO.pdf.

2. Crump JA, Mintz ED. Global trends in typhoid and paratyphoid fever. Clin Infect Dis 2010; 50:241-6.

3. World Health Organization. Special theme issue: prevention and control of childhood pneumonia. Buletin WHO 2008;86:321-46.

4. Behl P, Gupta V, Sachdev A, Guglani V, Chander J. Pattern in antimicrobial susceptibility of Salmonellae isolated at a tertiary care hospital in northen India. Indian J Med Res 2017;145:1248.

5. Ringo-Ringo PH. Pola resistensi antibiotik pada penderita demam tifoid anak di Bagian Ilmu Kesehatan Anak FKUI RSCM Jakarta Tahun 1990-1994, tesis. Jakarta: Program Studi ilmu Kesehatan Anak Fakultas Kedokteran Universitas Indonesia, 1996.

6. Hadinegoro SR. Masalah multiple drug resistance pada demam tifoid anak. Cermin Dunia Kedokt 1999;124:5-10.

7. Hasibuan SI. Karakteristik penderita demam tifoid rawat inap di rumah sakit Sri Pamela PTPN 3 Tebing Tinggi tahun 2004-2008, skripsi. Medan: Fakultas Kesehatan Masyarakat Universitas Sumatera Utara, 2009.

8. Modi R. Clinical profile and treatment outcome of typhoid fever in children at a teaching hospital, Ahmedabad, Gujarat, India. Int J Med Sci Pub Health 2016;5:212-16.

9. Comeau JL, Tran TH, Moore DL, Phi CM, Quach C. Salmonella enterica serotype typhi infections in a Canadian pediatric hospital: a retrospective case series. CMAJ Open 2013;1:E56-61.

10. Koul PB, Murali MV, Sharma PP, Ghai OP, Ramchandran VG, Talwar V. Multi drug resistant Salmonella typhi infection: clinical profile and therapy. Indian Pediatr 1991;28:357-61.

11. Malik AS, Malik RH. Typhoid fever in Malaysian children. Med J Malaysia 2001;56:478-90.
12. Patankar N, Shah I. Age related clinical and laboratory manifestation of enteric fever in children. JK Sci 2009;11:119-22.

13. Taneja PN, Ghai K. Clinical study of enteric fever. Indian Pediatr 1997;34:237-9.

14. Ugas MB, Carroll T, Kovar L, Chavez-Bueno S. Salmonella Typhi-induced septic shock and acute respiratory distress syndrome in a previously healthy teenage patient treated with high-dose dexamethasone. J Investig Med High Impact Case Rep 2016;4:1-5.

15. Sidabutar S, Satari HI. Pilihan terapi empiris demam tifoid pada anak: kloramfenikol atau seftriakson? Sari Pediatri 2010;11:434-9.

16. Rampengan NH. Antibiotik terapi demam tifoid tanpa komplikasi pada anak. Sari Pediatri 2013;14:271-6.

17. Musnelina L, Afdhal AF, Gani A, Andayani P. Pola pemberian antibiotika pengobatan demam tifoid anak di rumah sakit Fatmawati Jakarta tahun 2001-2002. Makara 2004;8:27-31.

18. Hartoyo, E, Yunanto A, Budiarti L. Uji sensitivitas Salmonella Typhi terhadap berbagai antibiotik di bagian anak RSUD Ulin Banjarmasin. Sari Pediatri 2006;8:118-21.

19. Kalbe Academia Highlight. Terapi terkini demam tifoid. CDK 2014;41:465.

20. Erviani AE. Analisis multidrug resistensi terhadap antibiotik pada Salmonella Typhi dengan teknik multiplex PCR. Biogenesis 2013;1:51-60.

21. Moosa A, Rubidge CJ. Once daily ceftriaxone vs chloramphenicol for treatment of typhoid fever in children. Pediatr Infect Dis J 1989;8:696-9.

22. Acharya G, Buttler T, Ho M, Sharma PR, Tiwari M, Adhikari RK dkk. Treatment of typhoid fever: randomized trial of a three-day course of Ceftriaxone versus a fourteen day course of chloramphenicol. Am. J Trop Med Hyg 1995;52:162-5.

23. Tatli MM, Guler G, Kosecik M, Yilmaztatli A. Treatment of typhoid with a flexible-duration of ceftriaxone compared with 14-day treatment with chloramphenicol. Int J Antimicrob Agents 2003;21:350-3.

24. Kumar R, Gupta N, Shalini. Multidrug- resistant typhoid fever. Int J Pediatr 2007:24:39-42.

25. Girgis NI, Sultan Y, Hammad O, Farid Z. Comparison of the efficacy, safety and cost of cefixime, ceftriaxone and aztreonam in the treatment of multidrug-resistant Salmonella typhi septicemia in children. Pediatr Infect Dis J 1995;14:603-5.

26. Musnelina L, Afdhal AF, Gani A, Andayani P. Analisis efektivitas biaya pengobatan demam tifoid anak menggunakan kloramfenikol dan seftriakson di rumah sakit Fatmawati Jakarta tahun 2001-2002. Makara 2004;8:59-64. 